\title{
A importância da tectônica transcorrente no alojamento de granitos pré a sincolisionais na região do vale do médio Rio Doce: o exemplo das suítes graníticas Galiléia e Urucum
}

\author{
Herminio Arias Nalini Jr' ${ }^{1}$, Rômulo Machado ${ }^{2}$, Issamu Endo ${ }^{3}$ \& Essaid Bilal ${ }^{4}$
}

\begin{abstract}
Resumo As suítes Galiléia (granito tipo-I) e Urucum (granito tipo-S), respectivamente, com idades $\mathrm{U} / \mathrm{Pb}$ em zircão de $594 \pm 6$ Ma $584 \pm 2$ Ma Ma, situam-se na região do Médio Vale do Rio Doce, na porção leste de Minas Gerais, entre as cidades de Governador Valadares (MG) e Colatina (ES). Caracterizam-se por batólitos alongados (NW-SE e N-S) e associados à Zona de Cisalhamento de Alto Ângulo de Conselho Pena-Resplendor. Possuem estruturas magmáticas e outras desenvolvidas no estado sólido, e lineação magmática bem desenvolvida com caimento para $\mathrm{Ne} \mathrm{NE}$ (entre 10 e $30^{\circ}$.) e para S e SW (inferior a $25^{\circ}$.). Foram reconhecidas duas fases principais de deformação: a primeira foi responsável pela foliação no estado sólido e lineação magmática nas suítes graníticas e pela xistosidade e lineação de estiramento nas rochas encaixantes (xistos São Tomé), e a segunda foi responsável por uma clivagem de crenulação de natureza extensional e outras estruturas associadas. A análise cinemática mostra uma forte correlação entre o regime transcorrente e as intrusões graníticas.
\end{abstract}

Palavras-chave: colocação de granitos, granitos brasilianos, tectonica transcorrente.

\begin{abstract}
The importance of the strike-slip tectonic in the pre-to sin-colisional granite emplacement in the middle Rio Doce valley: Galiléia and Urucum suites. The Galiléia and Urucum suites, respectivelly, with $594 \pm 6 \mathrm{Ma}$ and $584 \pm 2 \mathrm{Ma}$ zircon $\mathrm{U}-\mathrm{Pb}$ ages, are situated in the middle region of the Rio Doce Valley, eastern of Minas Gerais State. They are characterized by elongated batholiths in the NW-SE and $\mathrm{N}-\mathrm{S}$ trending associated with high angle shear zone of Conselho Pena-Resplendor. The batholiths present solidstate and magmatic flow foliations and a well-developed magmatic lineation. Two deformation phases were described: the first was responsible by the development of a solid-state foliation and magmatic flow lineation in the granitic suítes and a schistosity and stretching lineation in the country rocks (São Tomé schist), and the second was responsible by an extensional crenulation cleavage and other associated structures. Kinematic analysis indicates that the Galiléia and Urucum suites were emplaced along of transcurrent structures.
\end{abstract}

Keywords: granite emplacement, Brazilian granites, strike-slip tectonic.

INTRODUÇÃO A região aqui estudada localiza-se no médio vale do Rio Doce, entre as cidades de Galiléia (MG) e Colatina (ES) (Fig. 1). Em termos geotectônicos, encontra-se inserida no segmento central da Faixa Araçuaí (sensu Pedrosa-Soares \& Wiedeman-Leonardos 2000, Pedrosa-Soares et al. 2001) ou Província Mantiqueira Setentrional (Almeida \& Hasui 1984). Este segmento faz parte do domínio interno da referida faixa (Setor Oriental, Siga Jr. 1986), onde as estruturas regionais possuem orientação geral ao redor de N-S e NNW, sendo aí marcadas por expressivas zonas de cisalhamento dúcteis de alto ângulo, como a de Resplendor-Conselheiro Pena (Nalini 1997).

Os primeiros trabalhos realizados sobre o segmento aqui estudado, do vale do Rio Doce, não tiveram como objeto principal o estudo estrutural e tectônico das rochas graníticas, mas sim objetivaram estudos envolvendo particularmente os aspectos mi- neralógicos e de exploração econômica dos pegmatitos (Barbosa et al. 1964; Silva et al. 1987; Fanton et al. 1978; Moura et al. 1978a e b; Issa Filho et al. 1980). Paralelamente, tais trabalhos contemplam uma abordagem geral da estratigrafia e da tectônica, porém numa relação compatível mais com uma escala de reconhecimento regional.

Os principais projetos de cartografia geológica regionais foram executados pelo Radambrasil e pela CPRM -Serviço Geológico do Brasil, com os mapas geológicos sendo gerados em escalas 1: 1.000.000 (Folha SE-24, Rio Doce), 1: 250.000 (Projeto Jequitinhonha) e 1: 100.000 (PLGB- Projeto de Levantamento Geológico Básico). A partir destes projetos, foram reconhecidas três unidades litoestratigráficas maiores (Silva et al. 1987): os complexos arqueanos (Juiz de Fora e Pocrane) e as unidades do Proterozóico Inferior (Complexo Paraíba do Sul e Gnaisse Piedade) e Proterozóico

\footnotetext{
1 - Universidade Federal de Ouro Preto, Departamento de Geologia, Ouro Preto (MG), Brasil. E-mail: nalini@degeo.ufop.br

2 - Universidade de São Paulo, Instituto de Geociências, São Paulo (SP), Brasil. E-mail: rmachado@usp.br

3 - Universidade Federal de Ouro Preto, Departamento de Geologia, Ouro Preto (MG).

4 - École des Mines de Saint Etienne, França.
} 

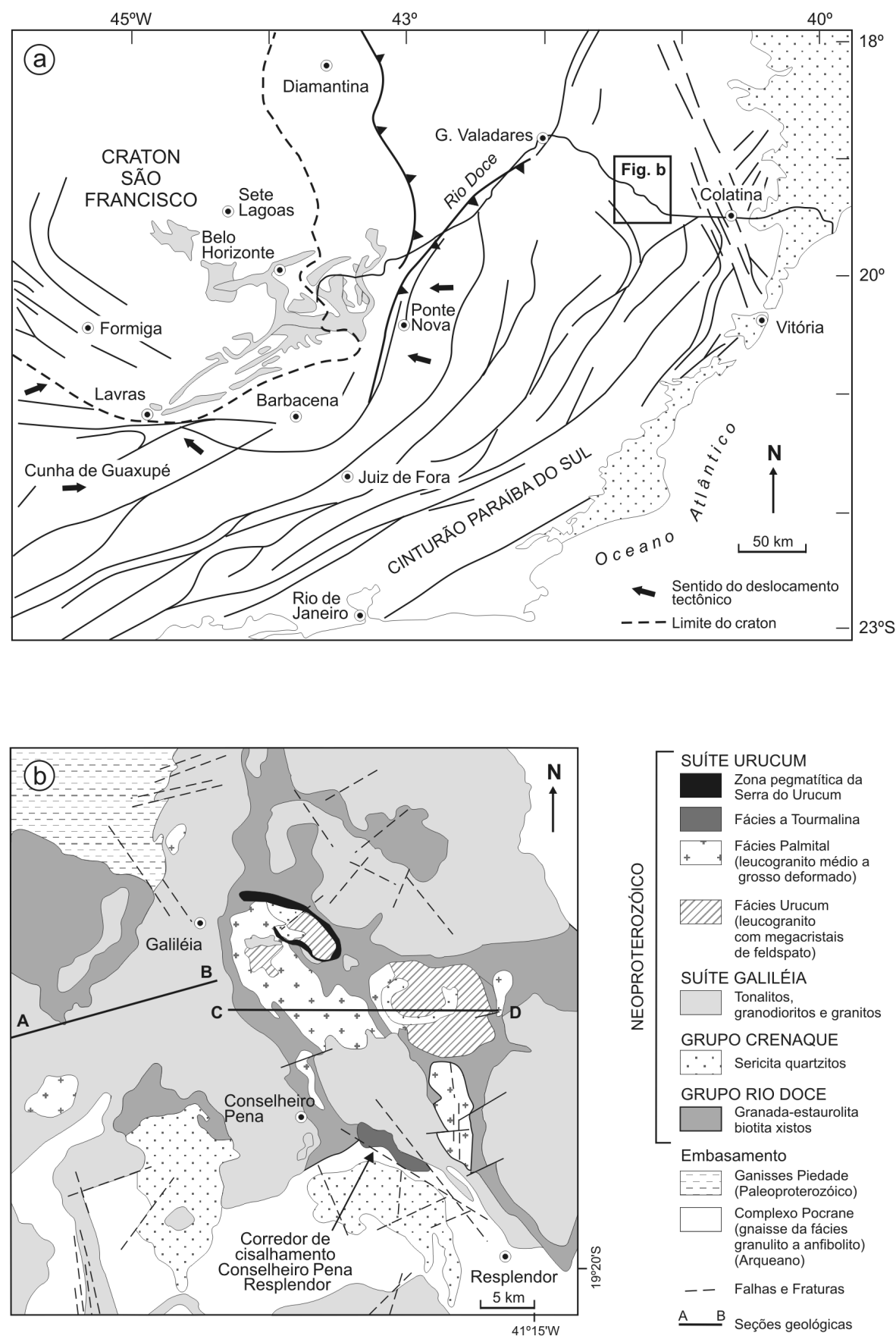

Figura 1 - Mapa geológico da região do médio Rio Doce (mod. de Silva et al. 1987, Barbosa et al. 1964, Endo 1997 e Nalini 1997) contendo a posição dos perfis geológicos realizados.

Superior/Cambriano (Grupos São Tomé e Crenaque, e as suítes graníticas Galiléia e Urucum). Os dois primeiros complexos representam as rochas do embasamento da região, sendo afetadas por metamorfismo em fácies anfibolito a granulito.

Dados U/Pb de alta resolução (em zircão, pelo método SHRIMP) obtidos em rochas do embasamento do núcleo do Orógeno Araçuaí (granulito charnockito do alto Caparaó) forneceram idades, respectivamente, de $2195 \pm 15 \mathrm{Ma}$ e de $590 \pm 79 \mathrm{Ma}$, a primeira interpretada como a idade de cristalização magmática e a segunda indicadora de metamorfismo (Silva et al. 2002). Duas outras idades foram obtidas pelos autores em anfibolitos do Complexo Pocrane: uma de $1560 \pm$ $14 \mathrm{Ma}$ e outra de $602 \pm 14 \mathrm{Ma}$. Tais idades foram interpretadas também da mesma forma.

Com o objetivo do melhor entendimento da importância das rochas graníticas do médio Rio Doce na evolução do magmatismo pré- a sincolisional da Faixa Araçuaí, realizou-se um estudo pormenorizado de geologia estrutural das suítes graníticas Galiléia e Urucum. Neste trabalho mostra-se que a colocação de ambas as 
suítes foi controlada por zonas de cisalhamento de alto ângulo, sendo a primeira delas associada à uma componente destral/inversa, e a segunda, à uma componente destral/normal.

TRABALHOS ANTERIORES Coube a Barbosa $e t$ al. (1964) o pioneirismo na identificação das estruturas mesoscópicas da região, bem como a caracterização dos granitóides da suíte Galiléia como sendo intrusivos nos Grupos São Tomé e Crenaque. Descrevem a existência de injeção de corpos de tonalitos e de pegmatitos nos xistos.

Moura et al. (1978a e b) e Issa Filho et al. (1980) reconheceram na região leste de Galiléia uma estrutura braquianticlinal com orientação NW, contendo no seu interior o Maciço Urucum. Os autores reconheceram três foliações, denominadas respectivamente de S1, S2 e S3, que foram associadas à fases de deformações sucessivas. Uma superfície de variação composicional foi considerada estratificação sedimentar sendo denominada de superfície-S. A S1 é descrita como foliação plano-axial a dobras subverticais com direção aproximadamente N-S e a S2 é caracterizada como uma clivagem de crenulação presente nos níveis peliticos. Foram identificadas duas lineações de intersecção: uma (L1) entre as superfícies $\mathrm{S} 1 / \mathrm{S}$, representada também por minerais alongados e outra resultante da intersecção da superfície S2 com a superfície S1, produzindo uma lineação de crenulação denominada L2.

Silva et al. (1987) caracterizam a região do Rio Doce como sendo um domínio marcado por deformações polifásicas associadas a eventos de migmatização e de intrusão granítica. Várias dobras em escala regional foram identificadas com o desenvolvimento de uma xistosidade associada (NE a NW) cortadas por um sistema de falhas subverticais com direção N60E (Lineamento Ipanema-Nova Venécia) de idade contemporânea à zona de transcorrência de São Paulo (Hasui et al. 1975).

Vieira et al. (1993) descrevem, na porção sudeste da região estudada, cinco fases de deformação: as mais precoces são referidas como associadas a eventos tectônicos tangenciais e as mais tardias são relacionadas ao cisalhamento transcorrente ligado provavelmente ao lineamento de Guaçuí.

\section{GRANITÓIDES NEOPROTEROZÓCOS DO} VALE DO RIO DOCE São poucas as sínteses regionais disponíveis sobre as suítes graníticas neoproterozóicas da faixa Araçuaí na região do Vale do Rio Doce, sendo mais comuns artigos sobre maciços isolados (Siga Jr. 1986, Nalini 1997, Bilal et al. 1998, Féboli 1993 a e b, Silva 1993, Pedrosa Soares et al. 1999, Nalini et al. 2000 a e b, Pedrosa-Soares \& Wiedemann-Leonardos 2000, Martins 2000, Martins et al. 2004, Mello 2000, Nalini et al. 2005). Estes abordam principalmente os aspectos petrográficos, litogeoquímicos, geocronológicos e, mais raramente, estruturais e tectônicos.

Os resultados do Projeto de Levantamento Geológico Básico -PLGB realizados pela CPRM na região do Vale do Rio Doce, em escala 1: 100.000, Folhas
Baixo Guandu e Colatina, permitiram a divisão dos maciços granitóides da região em três grupos tectônicos principais: (1) maciços pré- a sin-tangenciais; (2) maciços sin-transcorrentes e, (3) maciços pós-transcorrentes (Tuller 1993, Vieira 1993).

No primeiro grupo foram incluídos os maciços mais deformados, dispostos concordantemente às estruturas regionais. São batólitos lineares, de composição expandida (tonalito-granodiorito-granito), de características geoquímicas cálcio-alcalinas e meta-aluminosas, considerados como pré- a sincolisionais, tendo evoluído em ambientes de arco vulcânico e intraplaca. O segundo grupo é representado por maciços alongados, de dimensões batolíticas, que possuem foliação milonítica nas bordas, passando para uma estrutura isótropa na parte central. (Vieira 1993). Possuem basicamente as mesmas características geoquímicas do grupo anterior, apresentando porém termos peraluminosos e caráter tectônico pós-colisional. No terceiro grupo são incluídos maciços menores, de forma anelar e ovalada, zonados e concêntricos, sendo comum associação de rochas charnockíticas, básicas, intermediárias e ultrabásicas (Maciços Aimorés, Lagoa Preta, Ibituba, dentre outros). Este grupo é caracterizado como granitos tipoI, cálcio-alcalinos e toleíticos, de ambiente intraplaca e arco vulcânico, ou ainda pós-orogênico e de soerguimento pós-colisional (Tuller 1993, Vieira 1993).

Os dados geocronológicos $(\mathrm{U} / \mathrm{Pb}$ e $\mathrm{Pb} / \mathrm{Pb})$ existentes sobre este magmatismo apontam idades no intervalo de 500 a $595 \mathrm{Ma}$ (Bilal et al. 1998, Noce et al. 1999, Noce \& Macambira 2000, Nalini et al. 2000a). Estes, juntamente com os dados $\mathrm{Rb} / \mathrm{Sr}$, permitiram dividir os granitos em três grupos: (1) granitóides sin- a tardi-tectônicos $(650$ - $550 \mathrm{Ma})$; (2) tardi- a pós-tectônicos $(550-500 \mathrm{Ma})$ e, (3) pós-tectônicos $(500-450$ Ma) (Siga Jr. 1986).

Posteriormente (Bilal et al. 1998), este magmatismo foi dividido em quatro grupos tectônicos: (i) prétectônicos, representados pela suíte Galiléia, com idade $\mathrm{U} / \mathrm{Pb}$ de $595 \mathrm{Ma}$; (ii) sintectônicos, representados pela suíte Urucum, com idade $\mathrm{U} / \mathrm{Pb}$ de $582 \mathrm{Ma}$; (iii) tardi a pós-tectônicos, englobando os complexos intrusivos anelares como Aimorés e Ibituba-Itapina, com idades entre 537 e $520 \mathrm{Ma}$ e, (iv) pós-tectônicos, representados pelo Sienito Ibituruna, com idade $\mathrm{Rb} / \mathrm{Sr}$ de $511 \mathrm{Ma}$.

Mais recentemente, o magmatismo granítico da faixa Araçuaí foi dividido em cinco suítes (G1 a G5) (Pedrosa Soares \& Wiedemann-Leonardos 2000). A suíte G1 possui características pré-colisionais (entre 625 a $595 \mathrm{Ma}$ ). A origem da suíte G2 é relacionada a anatexia regional ocorrida em rochas metassedimentares durante o espessamento crustal, com geração da suíte G3 no estágio tardio do processo. As suítes G1 e G4 são relacionadas a estágios sucessivos de maturação de um arco magmático continental. A primeira delas representaria a raíz deste arco, sendo vinculada a uma zona de subducção mergulhando para leste (Pedrosa Soares et al. 1998 a,b, 1999), enquanto a segunda, gerada em nível crustal profundo, é relacionada à interação crosta/ manto. A suíte G5, de colocação mais rasa (6 a 12 km) 
do que as anteriores, teria sido gerada em regiões de crosta espessada (Pedrosa Soares et al. 1999).

Datações $\mathrm{Pb} / \mathrm{Pb}$ (em zircão, TIMS pelo método de evaporação) recentes, realizadas em seis maciços das suítes G1, G2 e G5, forneceram as seguintes idades: G1/G2- $591 \pm 4 \mathrm{Ma}$ (Ataléia); $582 \pm 5 \mathrm{Ma}$ (Wolf), $595 \pm 3$ Ma (Brasilândia); $575 \pm 2$ Ma (Guarataia); 576 \pm 5 Ma (São Vitor/Pescador); G5- $519 \pm 2$ Ma (Caladão/ Padre Paraíso) e $503 \pm 9$ Ma (graníticos que cortam o maciço Caladão) (Noce et al. 1999 e Noce \& Macambira 2000).

Datações $\mathrm{U} / \mathrm{Pb}$ de alta resolução (em zircão, SHRIMP) em quatro granitóides foliados do Orógeno Araçuaí correlacionados a suíte G2 de Pedrosa Soares \& Wiedemann-Leonardos (2000) forneceram idades entre 560 a $570 \mathrm{Ma}$, consideradas como idades do magmatismo sincolisional do referido orógeno (Silva et al. 2002).

$\mathrm{Na}$ porção leste da região estudada, no estado do Espírito Santo, foi caracterizado o "arco magmático Rio Doce", de idade brasiliana, desenvolvido no intervalo de 590 a $480 \mathrm{Ma}$ (Figueiredo \& Campos Neto 1993), e que corresponde ao mesmo arco magmático definido também por Wiedemann (1993). Os primeiros autores dividem este magmatismo em pré-colisional (590 a 570 Ma), sincolisional (560 a $530 \mathrm{Ma}$ ) e pós-colisional (520 e $480 \mathrm{Ma}$ ), enquanto o último autor divide em sinorogênico (590 a 580 Ma) e tardi a pós-orogênico (520 a 450 Ma).

$\mathrm{O}$ primeiro trabalho sistemático envolvendo cartografia geológica sobre os granitóides das suítes Galiléia e Urucum foi realizado por Barbosa et al. (1964). A primeira suíte foi denominada de Tonalito Galiléia, sendo distinguida fácies petrográficas constituídas de quartzo dioritos a granitos, e, eventualmente, granodioritos. Os enclaves máficos, ocupando de 10 a $20 \%$ da superfície do referido tonalito, foram interpretados como restitos poupados do processo de anatexia, considerado pelos autores como responsável também pela origem dos tonalitos.

Os autores descrevem o caráter concordante do Tonalito Galiléia com a foliação dos xistos São Tomé, caracterizado como contato do tipo definido e marcado às vezes por injeção de corpos de tonalitos nos xistos, considerando então como intrusivo nos Grupos São Tomé e Crenaque. Estas rochas foram também relacionadas ao complexo granitóide associado à Associação Barbacena-Paraíba do Sul (Fontes et al. 1978), sendo posteriormente denominada Suíte Intrusiva Galilélia e definida como rochas de composição variando de quartzo-tonalito a granito, associados aos leucogranitos (Silva et al. 1987). Na região do Baixo Guandu, ela foi definida como constituída por tonalitos, trondhjemitos e granodioritos, e considerada como de colocação sin a tardi-cisalhamento, com idade atribuída ao Proterozóico Superior (Vieira et al. 1993).

O termo Granito Urucum foi utilizado por Barbosa et al. (1964) para designar granitos a duas micas, situados a leste de Galiléia, no interior da Serra de Urucum, sendo então descritos como de granulação grossa, mostrando, às vezes, uma foliação muito forte. São leucocráticos a mesocráticos, e apresentam uma textura porfirítica (Moura et al. 1978b). Os cristais de feldspato potássico podem alcançar até $10 \mathrm{~cm}$ de comprimento. O Granito Urucum é comumente megaporfirítico e os megacristais de oligoclásio e de microclínio perfazem de 30 a $80 \%$ do volume total da rocha.

O Granito Urucum foi também incluído inicialmente no complexo granitóide da Associação Barbacena - Paraíba do Sul, sendo depois denominado Suíte Urucum, que incluía ainda o Granodiorito Palmital (Barbosa et al. 1964) e pegmatitos associados (Silva et al. 1987). Enclaves dos xistos do Grupo São Tomé foram descritos nesta suíte. Os autores propuseram para estas rochas uma origem por anatexia em condições epi a mesozonal da base dos Grupos São Tomé e Crenaque, e também de uma parte do Complexo Pocrane.

ESTUDOS REALIZADOS O estudo geométrico e cinemático das suítes graníticas Galiléia e Urucum teve por objetivo a caracterização da organização estrutural interna dos corpos que integram estas suítes e sua relação com as rochas encaixantes. Paralelamente foram realizados perfis geológicos regionais (Fig. 2) no sentido de caracterizar a natureza e a hierarquia das estruturas encontradas regionalmente visando correlacioná-las com o quadro tectônico de colocação das suítes graníticas e dos pegmatitos associados. Durante este estudo 124 pontos foram descritos utilizando-se os procedimentos de análise geométrica descritos em Turner \& Weiss (1968).

Considerando que o tipo de trama interna resultante no seu momento de colocação de um corpo granítico passa a ser função fundamentalmente das relações de reologia entre o magma e a rocha encaixante, podese observar tanto estruturas formadas durante o estado sólido quanto durante o estado magmático, conforme os conceitos definidos por Arzi (1978) e Van der Molen \& Paterson (1979).

\section{ANÁLISE ESTRUTURAL}

Suíte Galiléia A estruturação interna da suíte granitóide Galiléia é marcada pela presença sistemática de uma foliação gerada em condições de estado sólido, denominada de $\mathrm{S}_{\mathrm{nG}}(\mathrm{G}=$ Galiléia $)$ e, mais raramente, por estruturas magmáticas preservadas.

As estruturas magmáticas são caracterizadas macroscopicamente pela alternância de leitos ricos em anfibólios e biotita ou ainda por plagioclásio e, microscopicamente, por um alinhamento sutil de plagioclásio zonado e/ou anfibólio. Contudo, tais estruturas são relativamente raras e, muitas vezes, de difícil identificação, razão pela qual não foram medidas sistematicamente.

A foliação $S_{n G}$ é caracterizada por uma orientação preferencial dos minerais, sobretudo de biotita. Esta foliação é localmente muito pronunciada e assume caráter milonítico (protomilonito) com recristalização dinâmica de cristais de quartzo. Na maior parte dos afloramentos possui uma orientação NW com mergulhos médio a elevados (entre $50^{\circ}$ a $80^{\circ}$ ) para NE ou SW (diagrama da Fig. 2, secção A-B). Grande parte das lineações minerais observadas (sobretudo biotita e agregados de quartzo) 

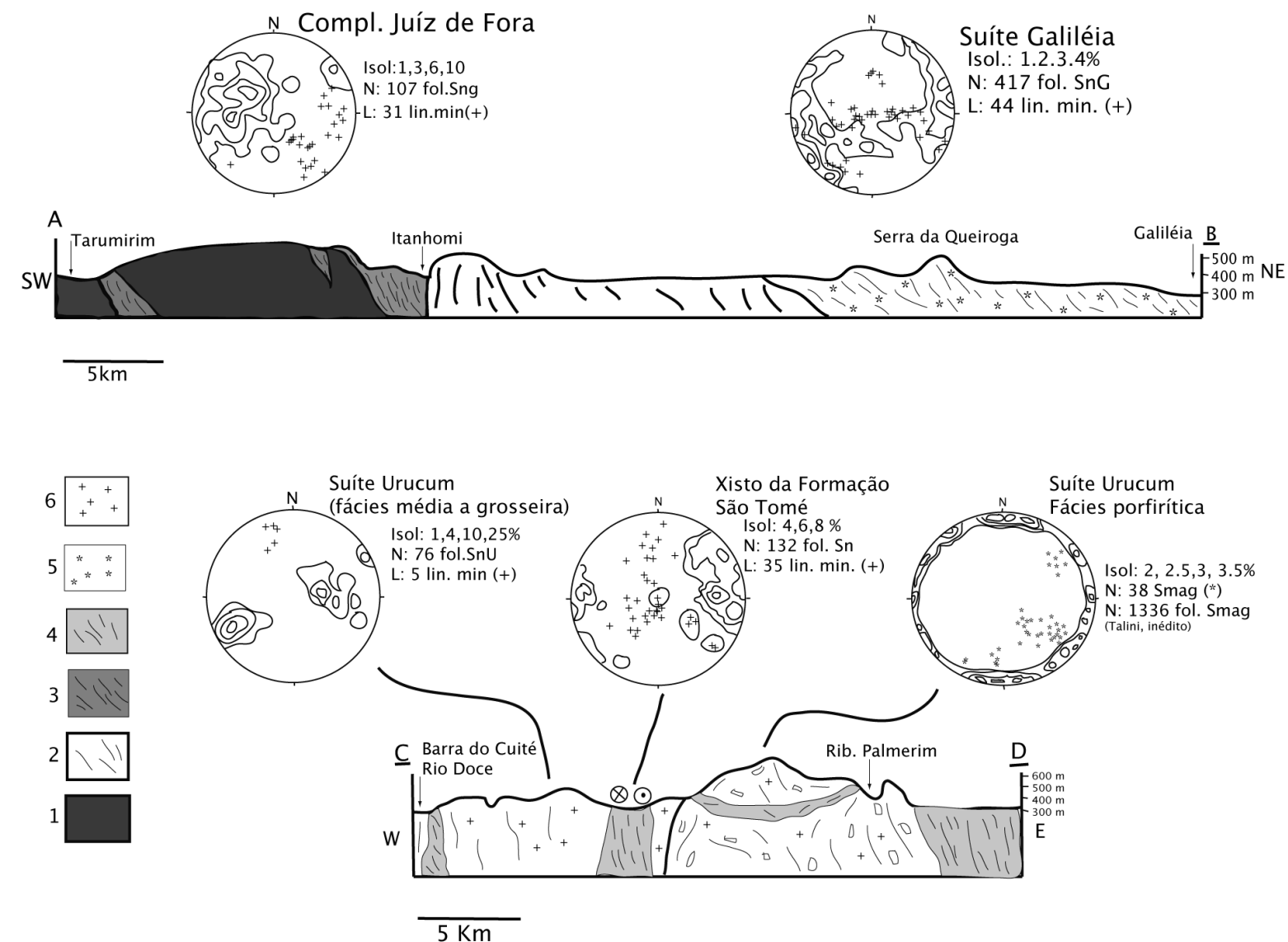

Figura 2 - Secções geológicas levantados na região do médio Rio Doce e respectivos diagramas estereográficos. A localização de cada perfil se encontra indicada na figura 1. Legenda: 1- Complexo Juiz de Fora; 2- Comlexo Pocrane; 3- Complexo Paraíba do Sul; 4-Xistos da Formação São Tomé; 5 - Suite São Tomé, 6- Suite Urucum.

possue caimento médio a elevado para E-NE ou para W-SW, sugerindo a atuação de componente oblíqua durante a colocação dessas rochas.

Os granitóides da suíte Galiléia encerram inúmeros enclaves máficos de forma achatada (oblata),. Os enclaves de composição granodiorítica, no corredor de cisalhamento Galiléia-Resplendor, mostram um eixo de estiramento médio com orientação $\mathrm{N} 30^{\circ}-60^{\circ} \mathrm{W} / 20^{\circ}-35^{\circ}$, e um plano de achatamento (XY) orientado segundo $\mathrm{N} 0^{\circ}-30^{\circ} \mathrm{W} / 35^{\circ}-45^{\circ} \mathrm{SW}$. A foliação $\mathrm{S}_{\mathrm{nG}}$ dos granitóides apresenta sistematicamente mergulho mais suave que o plano de achatamento dos enclaves. A lineação de estiramento mineral (biotitas e agregados alongados de quartzo recristalizado) tem uma direção $\mathrm{S} 25^{\circ} \mathrm{W} / 22$. Esta lineação encontra-se impressa sobre a superfície dos enclaves e assemelha-se a lineação de intersecção entre a superfície-S (xistosidade) e a superfície-C (superfície de cisalhamento), indicando localmente movimentos normais.

A oeste, a geometria dos enclaves (Fig. 3) é diferente, indicando movimentos inversos com componente destral, com a foliação dos enclaves sendo seccionada pela foliação-C (Figs. 3B e C).
Suíte Urucum A estruturação mesoscópica dos granitos da suíte Urucum está representada essencialmente pela interação de uma foliação de fluxo magmático (Smag), produzida pelo efeito dinâmico do estágio magmático, e de uma xistosidade $\left(\mathrm{S}_{\mathrm{nU}}\right)(\mathrm{U}=$ Urucum$)$, produzida pela deformação regional, após a cristalização do magma. Para determinação da transição entre a foliação magmática e a foliação no estado sólido foram usados os critérios sugeridos em Paterson et al. (1989). Da mesma forma, utilizou-se também os trabalhos de Vauchez (1980), Guillet et al. (1985) e Guinebertau et al. (1987) para o estudo textural do quartzo, o qual é o melhor marcador da transição entre os estados magmático/sólido de assembléias mineralógicas de rochas graníticas

A foliação $S_{\text {mag }}$ é bem preservada particularmente nos granitos megaporfiríticos (especialmente no corpo do rib. Palmerim) onde é materializada pela orientação preferencial de megacristais de feldspato potássico (Vernon, 1986). Geometricamente, a trajetória da $\mathrm{S}_{\mathrm{mag}}$ tende a mostrar localmente contornos aproximadamente circulares e com disposição paralela ao contato com os xistos da Formação São Tomé (Fig. 1 e 2, secção C-D). Regionalmente, a foliação da Formação São 


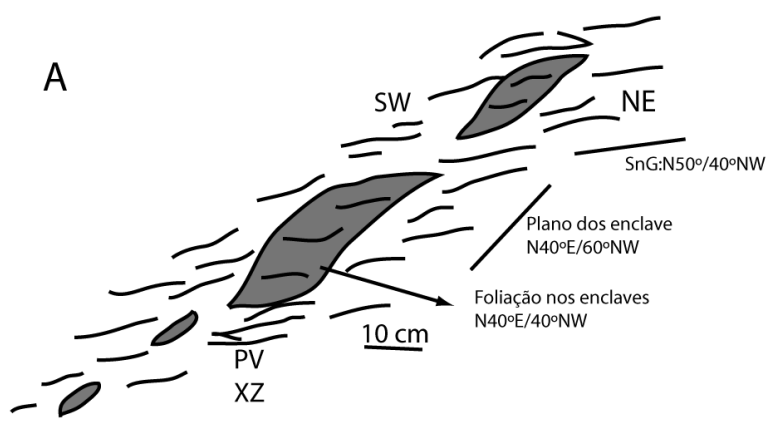

C

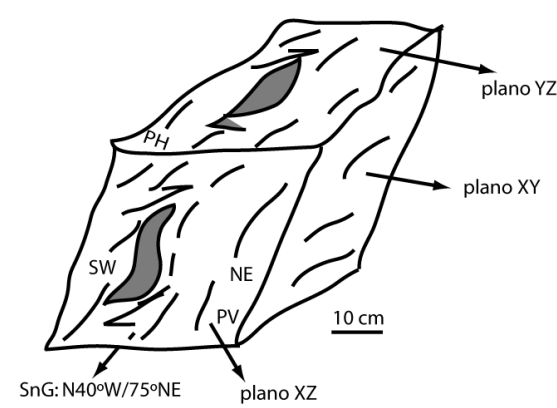

B

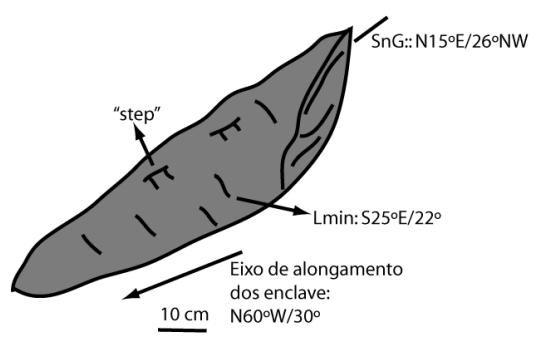

D

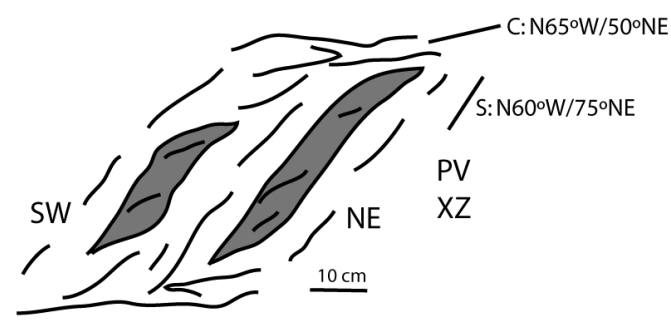

Figura 3 - Mesoestruturas nos granitóides da Suite Galiléia: A) diferença entre o mergulho da foliação $S_{n G}$ e o plano dos enclaves; B) "steps" (intersecção entre o plano S e o plano C) na superficie externa de um enclave indicando movimentos normais; $C$ ) bloco diagrama ilustando o movimento inverso com componente destral; D) morfologia dos enclaves mostrando a presença de movimentos de componente inversa.
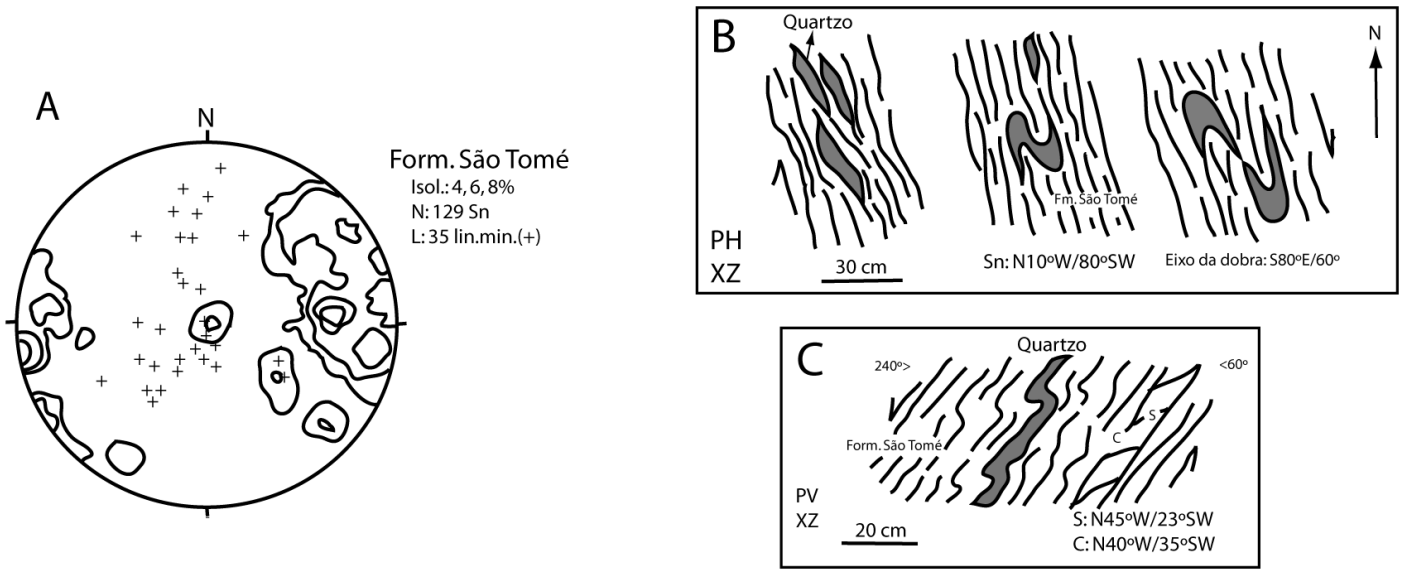

Figura 4 - Estruturas no xisto da Formação São Tomé: A) diagrama estereográfico das foliações e lineações de estiramento mineral nos xistos da Formação São Tomé; B) estruturas indicando movimentos destrais no xisto; $C$ ) estruturas sugerindo a presença de movimentos com componente normal.

Tomé apresenta atitude máxima $\mathrm{N} 36^{\circ} \mathrm{W} / 72^{\circ} \mathrm{SW}$ e lineação mineral com caimento moderado variando entre SW e NW (Fig. 4).

O pluton Palmerim é caracterizado por uma foliação de borda, com mergulho moderado a elevado, de forma ora com mergulhos para o interior do pluton ora para fora. Os demais corpos da suíte Urucum (grano- diorito Palmital), situados a oeste da corpo de Palmerim, mostram-se alongados, com eixo maior na direção NW. Nestes casos, a $S_{\text {mag }}$ possui orientação NW-SE e exibe mergulhos elevados. A variação da intensidade da recristalização dinâmica em escala microscópica e a presença de feldspatos deformados e indeformados, lado a lado, mostram que a recristalização ocorreu de 
maneira heterogênea e a $S_{\text {mag }}$ evoluiu para uma foliação de estado sólido paralela a foliação $\mathrm{SnG}$ dos granitóides da suíte Urucum e paralela à foliação $\mathrm{Sn}$ das rochas encaixantes, sobretudo próximos aos contatos.

Uma lineação de fluxo magmático $\left(\mathrm{L}_{\mathrm{mag}}\right)$ é definida pela orientação preferencial do eixo maior $(\mathrm{X})$ do feldspato potássico, que possui a mesma direção da foliação magmática.

Diferentes estágios de deformação no estado sólido são associados com a foliação $S_{\text {mag }}$ da suíte Urucum, como resultado do aumento progressivo da intensidade da deformação. Neste sentido, pode-se individualizar um estado de deformação precoce, marcado pela disposição planar de biotitas e moscovitas (foliação $\mathrm{S}_{\mathrm{nU}}$ ) e, outro, pela extinção ondulante do quartzo. Neste caso, a recristalização é rara. Esta foliação é paralela à $\mathrm{S}_{\mathrm{mag}}$ e passa ser geneticamente associada com a xistosidade Sn dos xistos encaixantes. Progressivamente, com intensidade de deformação mais avançada, ocorre uma intensa protomilitização da rocha, a qual é acompanhada pela recristalização dinâmica acentuada do quartzo e, muitas vezes, do microclínio da matriz, juntamente com a ocorrência de agregados elipsoidais de quartzo. Tais condições são compatíveis com temperaturas ao redor de $450^{\circ}$ (Tullis, 1983). Este estágio é caracterizado pelo aparecimento de estruturas S-C e de uma lineação de estiramento mineral $\left(\mathrm{L}_{\text {est-U }}\right)$, formada pelo estiramento dos agregados de quartzo e feldspatos recristalizados transformando a rocha granítica em protomilonitos.

$\mathrm{Na}$ maior parte dos afloramentos observam-se feldspatos potássicos idiomórficos que se cristalizaram posteriormente à deformação principal e, também, me- gacristais de feldspato de potássio com estirados, às vezes, rompidos e constituindo o núcleo de sombras de pressão. A presença simultânea destas texturas em escala microscópica podem sugerir variações na intensidade de deformação durante a cristalização e colocação dos corpos da suíte Urucum.

O fluxo de magma na interface plúton-encaixante gera movimentos que tendem a orientar os minerais paralelamente ao contato com as rochas hospedeiras. O sentido de imbricação dos feldspatos (tiling de DenTex, 1966; tuillage de Blumenfeld, 1983 e Blumenfeld \& Bouchez, 1988) (Fig. 5), as estruturas S-C, a assimetria das sombras de pressão ao redor dos feldspatos (Figs. $5 \mathrm{~A}, \mathrm{~B}, \mathrm{C}$ e D), dobras assimétricas em veios de quartzo ou em pegmatitos $(\mathrm{cm})$, juntamente com a intersecção entre S e C (steps) impressa na superfície de cisalhamento indicam que os granitóides da suíte Urucum foram submetidos a um regime de deformação não-coaxial associada com uma importante componente trans-tracional (destral/normal).

Pegmatitos Os pegmatitos são zonados, possuem uma forma em geral tabular e espessura variável, de alguns centimetros até dezenas de metros (Fig. 6). Os corpos são paralelos à xistosidade $\mathrm{Sn}$ dos xistos São Tomé. Além disso, muitos deles apresentam-se deformados, sendo dobrados, boudinados e falhados. Com base nas informações de campo, foi possível separar dois grupos de pegmatitos.

Os primeiros exibem dobras com assimetria em $\mathrm{Z}$, com eixo variável, com direção entre $\mathrm{N} 10^{\circ} \mathrm{W}$ e $\mathrm{N} 50^{\circ} \mathrm{W}$ e caimento entre $30^{\circ}$ e $50^{\circ}$ para NW e SE. Relações de

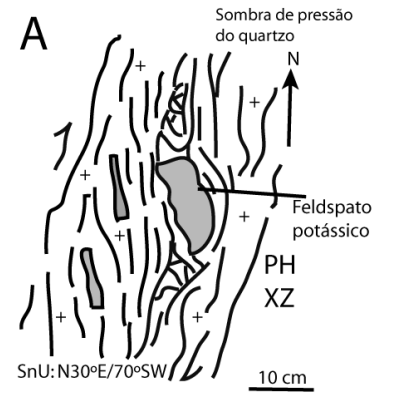

C

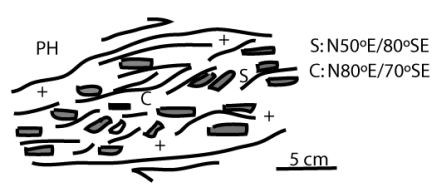

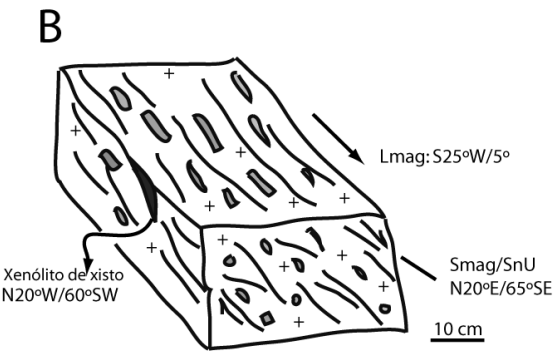

D

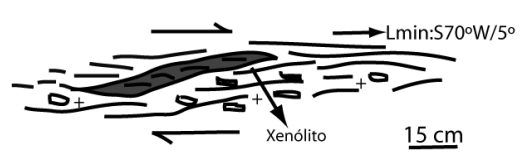

Figura 5 - Estruturas nos granitóides da Suite Urucum: A) sombra de pressão entorno de megacristal de feldspato potássico; B) bloco diagrama esquemático ilustrando movimento com componente normal no granito Urucum; C) imbricação de feldspatos potássicos indicando movimentos destrais; D) deformação de um xenólito de sisto São Tomé presente no interior do granito Urucum. 

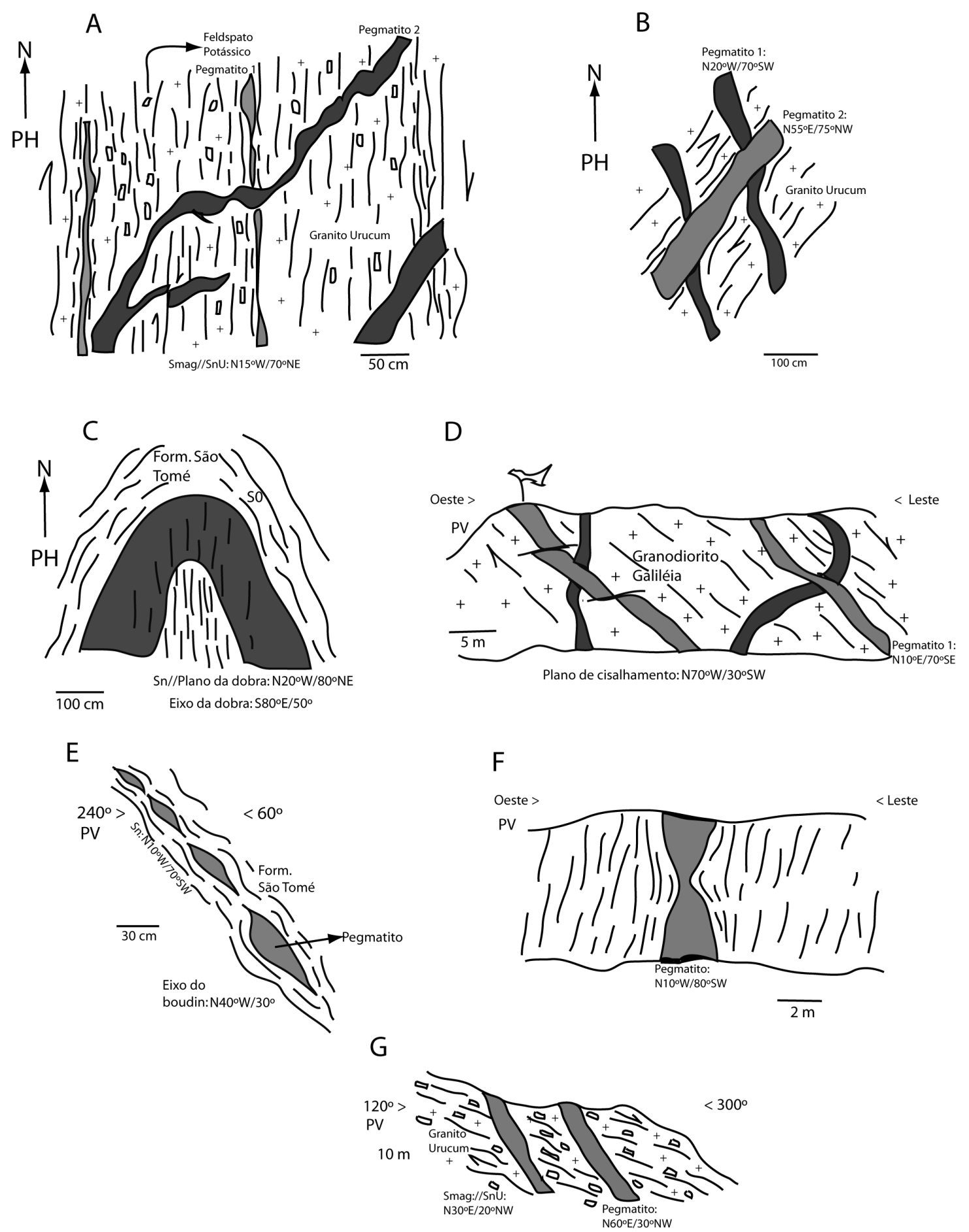

Figura 6 - Estilos estruturais observados nos pegmatitos da região de Conselheiro Pena - Galiléia: A) duas famílias de pegmatitos cisalhados indicando movimentos destrais; B) duas famílias de pegmatitos, sendo que a primeira se encontra cisalhada; $C$ ) pegmatito métrico com dobra fechada; D) duas familias de pegmatitos mostrando movimentos normais; E) estrutura do tipo "pinch and swell" no pegmatito; F) pegmatito métrico boudinado; G) pegmatito seccionando a foliação do granito Urucum (indicando movimento normal).

corte mostram claramente que são mais precoces do que o segundo grupo, e ocorrem sempre encaixados no xisto. A foliação plano-axial das dobras possui a mesma direção da xistosidade $\mathrm{Sn}$ regional $\left(\mathrm{N} 20^{\circ} \mathrm{W} / 78^{\circ} \mathrm{NE}\right)$.
Os corpos de pegmatitos boudinados exibem "necks" com orientação variável entre N-S a N50 W e caimentos de $20^{\circ}$ para $\mathrm{N}$ ou NW. São subparalelos à direção da xistosidade Sn dos xistos (Fig. 6) e, local- 
mente, são seccionados por falhas normais.

A análise geométrica das dobras, das estruturas de boudinage e das falhas normais, sugerem um quadro cinemático destral com movimentos normais tardios, os quais são compatíveis com a deformação regional observada nos xistos e em grande parte dos granitóides.

$\mathrm{Na}$ literatura geológica são descritas inúmeros exemplos de províncias pegmatíticas, cuja colocação são associadas a estruturas lineares comparáveis àquelas encontradas nos pegmatitos da região de GaliléiaConselheiro Pena, como na província Herciniana dos Apalaches (Kesler, 1976), na província oeste de PamirHindukush (Rossovskyi \& Chmyrev, 1977) e na região de English River e Quetico (Cerny, 1990).

Fases de Deformação A análise das estruturas dos granitóides das suítes Urucum e Galiléia, juntamente com a sua encaixante principal, permitiu identificar duas fases de deformação principais na região.

A primeira fase (D1) foi responsável pelo desenvolvimento da foliação no estado sólido nas rochas granitóides $\left(\mathrm{S}_{\mathrm{nG}}\right.$ e $\left.\mathrm{S}_{\mathrm{nU}}\right)$ e da xistosidade $\mathrm{Sn}$ dos xistos São Tomé, juntamente com uma lineação de estiramento mineral. Esta fase parece ter condicionado a foliação magmática $\left(\mathrm{S}_{\mathrm{mag}}\right)$ e a lineação de fluxo magmático, sobretudo na parte central dos granitos da suíte Urucum (fácies com megacristais de feldspato potássico). É interpretada como aquela que marca o episódio tectônico principal da região, quando ocorreu a colocação e deformação sin-tectônica dos diferentes tipos de granitos da suíte Urucum e, provavelmente, do batólito Galiléia. Esta interpretação é baseada nos seguintes elementos:

- paralelismo entre a foliação dos granitóides e dos xistos encaixantes, assim como da cinemática similar entre eles;

- intrusão de uma grande parte dos corpos da suíte Urucum (fácies Palmital) segundo a direção de elongação máxima do elipsóide de deformação (NW, paralela à foliação regional) (Nalini Jr. 2007);

- presença de pontos tríplices nas extremidades NW e SE dos corpos Palmerim (Fig.1), representando assim um forte argumento (Brun \& Pons, 1981; Lagarde et al., 1990) a favor de uma colocação dos granitos contemporâneos ao desenvolvimento da xistosidade dos xistos da Formação São Tomé.

Localmente, observa-se durante a fase D1 uma inversão cinemática, a qual se intensifica pela atuação de um cisalhamento sinistral impresso em afloramentos ricos em megacristais de feldspato potássico, a leste do corpo de Palmerim. Esta fase pode representar uma inversão cinemática local, em função da atuação da zona de cisalhamento de Vitória, conectadasituada a oeste, que desempenhou um papel importante na compartimentação tectônica da região.

A segunda fase de deformação (D2) foi responsável pela geração de uma clivagem de crenulação, de uma lineação de crenulação, e pelo desenvolvimento de falhas e de processos de boudinage. Esta fase pode ser interpretada como o resultado de componentes normais associadas a cinemática regional destral, como o resul- tado de um episódio extensional durante o período tardi- a pós-orogênico ou como o flaco invertido de uma dobra regional.

Em resumo, a região é marcada principalmente por movimentos transcorrentes dúcteis, destrais durante a fase D1 e, posteriormente, sinistrais com componente normal associada. Este modelo é compatível com o modelo tectônico que compatibiliza componentes transpressivas e trativas (no sentido de Sanderson \& Marchini 1984). Neste caso, a presença de cavalgamentos, dobramentos e transcorrências na região pode ser explicada como resultado de grandes falhas transcorrentes (zona de cisalhamento destral de Guaçuí e zona de cisalhamento sinistral de Vitória) associadas ao cinturão de cisalhamento Atlântico definido por Machado \& Endo (1993). Da mesma maneira, na região do Vale do Rio Doce, este cinturão mostra inversão cinemática, destral para sinistral.

Condições de Colocação das Suítes Graníticas A estrutura final de colocação dos corpos graníticos na crosta superior é controlada pela interferência do campo de deformação regional (forças tectônicas sin-colocação) e pelo campo de deformação local (força ascensional do magma) ligados aos efeitos da intrusão (Pitcher 1979, Brun 1981, Castro 1987, Hutton 1988, Lagarde et al. 1990). Deste modo, durante a colocação, os corpos graníticos registram a história tectônca regional como um marcador ativo (Brun \& Pons 1981).

De uma maneira geral, a ascensão do magma pode ocorrer através de um sistema de fraturas e/ou de falhas profundas (Shaw 1980, Marsh 1982, Etheridge et al. 1983, Clemens \& Mawer 1992, Petford et al. 1994) ou através de processo diapírico causado por diferença de densidade entre o magma e a rocha encaixante (Ramberg 1970, England 1990). Este aspecto é devidamente amparado em modelos experimentais, onde o contraste de resistência entre o magma e a rocha encaixante é pequeno.

$\mathrm{Na}$ literatura, inúmeros plútons têm sido caracterizados como cronológica e espacialmente associados a zonas de cisalhamento transcorrentes (batólito do Donegal, Pitcher \& Berger 1972, Hutton 1982; plútons de Ajaj, Davies 1982; granito Ratagein, na Escócia, Hutton \& McErlean 1991), em zonas transpressivas (Complexo de Ox Montains, McCaffery 1992; cadeia Cadomiana, NW da França, D'Lemos et al. 1992), intrusões em zonas de cisalhamento por mecanismos de baloneamento "balloning" (Bruns \& Pons 1981, Pons 1982) e fraturas ou zonas de cisalhamento extensionais (Castro 1987, Hutton et al. 1990, Paterson \& Fowler 1993).

No caso estudado, a forte correlação espacial observada entre os granitos e os pegmatitos, sobretudo da suíte Urucum, e a transcorrência (zona de Cisalhamento Galiléia-Resplendor) sugere que estas falhas tiveram um controle na ascensão e colocação dos magmas. O trabalho de Berdiel (1995) sugere que as intrusões magmáticas em regimes transcorrentes colocamse segundo a direção de elongação máxima do elipsóide de deformação $\left(\lambda_{1}\right)$, e que o local da colocação é definido deste os primeiros estágios da injeção. Isto pode explicar a disposição alongada da suíte Urucum e dos 
pegmatitos. A presença de uma rocha encaixante em condições dúcteis, como os xistos da Formação São Tomé, é capaz de acomodar uma parte da deformação produzida pela expansão do maciço, favorecendo assim a sua colocação. São exemplos deste tipo as intrusões de leucogranitos associadas às zonas de cisalhamento do maciço Armoricano, no NW da França (Hanmer \& Vigneresse 1980, Vigneresse \& Brun 1983).

A fase extensional D2, caracterizada na região, pode ser contemporânea ou ligeiramente posterior às transcorrências. Segundo esta hipótese, sugere-se um modelo de colocação dos granitóides da suíte Urucum na crosta superior ao longo de fraturas e/ou falhas crustais que teriam atuado após a fase de espessamento crustal que se seguiu à colisão, durante uma fase de relaxação crustal. Neste caso, os cavalgamento seriam secundários. Adicionalmente, durante a colocação destes granitos colisionais, o encurtamento crustal ligado à convergência continental seria acomodado sobretudo por falhas transcorrentes comparáveis àquelas descritas para a cadeia Hercínica do oeste da Europa por Lagarde et al. (1992).

Para o batólito Galiléia os dados disponíveis são ainda insuficientes para uma discussão mais precisa do cenário de sua colocação. Mesmo assim, alguns aspectos sobre a colocação podem ser evocados sobre este batólito. Os dados de campo e geocronolólicos (Nalini Jr. 1997) mostram que as rochas que integram esta suíte são cronologicamente anterior às da suíte Urucum e que ela foi afetada por uma foliação no estado sólido comparável geometricamente àquela dos xistos da Formação São Tomé e dos granitos Galiléia. Estas observações sugerem que o quadro geral de colocação da suíte Galiléia é, pelo menos, em parte, comparável ao da suíte Urucum.

CONCLUSÕES A região de Galiléia-Conselheiro Pena foi afetada por eventos termotectônicos ligados aos ciclos Transamazônico e Brasiliano. O primeiro, acha-se registrado em rochas do embasamento representadas na região pelos Complexo Juiz de Fora e Pocrane. Este evento foi responsável pela formação de rochas metamórficas de alto grau (incluindo fácies granulito) e pela regeneração de rochas formadas no ciclo anterior. O ciclo Brasiliano (900 a $500 \mathrm{Ma}$ ) foi responsável pela deformação e metamorfismo de sequências sedimentares (Grupos Rio Doce e Crenaque) em condições da fácies anfibolito inferior, com formação da paragênese com estaurolita-granada +- sillimanita, a qual é encontrada sobretudo nos xistos da Formação São Tomé (Nalini Jr. 2007).

Os estudos efetuados nas rochas graníticas e nas suas encaixantes permitiram definir alguns aspectos fundamentais na evolução tectônica da região, que são os seguintes:

1) presença de duas fases de deformação principais: a primeira, responsável pela geração de uma foliação e uma lineação no estado sólido impressa nas rochas encaixantes e nos granitos. Paralelamente, esta fase foi também responsável pela geração de uma foliação de fluxo magmático nos granitos da suíte Urucum (fácies de granulação média a grossa). Esta fase foi acompanhada de movimentos transcorrentes de natureza destral. Localmente, observa-se uma inversão cinemática marcada por estruturas associadas a dobras de arrasto, as quais nas rochas da suíte Urucum indicam uma movimentação transcorrente sinistral. A segunda fase de deformação foi responsável pela geração de uma clivagem de crenulação, juntamente com outras estruturas associadas como boudinage e falhas normais, relacionadas provavelmente a um evento extensional tardi- a pós-magmático;

2) a evolução da região está condicionada pela movimentação da zona de cisalhamento de Guaçuí (zona de cisalhamento destral) e pela progressão para oeste da zona de cisalhamento de Vitória (zona de cisalhamento sinistral);

3) a relação espacial entre os granitos e os pegmatitos da suíte Urucum e o corredor de cisalhamento Galiléia-Resplendor, juntamente com a forma alongada dos corpos graníticos desta suíte e o quadro cinemático similar observado nos granitos e nos xistos encaixantes, são indicativos de que os granitóides da suíte Urucum são sin-tectônicos à primeira fase de deformação e sua colocação foi controlada por falhas transcorrentes;

4) observam-se dois grupos principais de pegmatitos. As estruturas e a cinemática observadas nos pegmatitos são compatíveis com as do xisto e dos granitos;

5 ) as rochas do embasamento mostram uma história muito mais complexa. Entretanto, são observadas estruturas com geometria e cinemática comparáveis ao dos granitos e dos xistos, indicando assim o caráter de penetratividade regional das fases de deformações identificadas na região de Conselheiro Pena-Galiléia.

\section{Referências}

Arzi A.A. 1978. Critical phenomena in the rheology of partially melted rocks. Tectonophysics 44: 173-184.

Almeida F.F.M. \& Hasui Y. 1984. O Pré-cambriano do Brasil. Sao Paulo, Edgard Blücher, 378p.

Barbosa A.L.M., Sad J.H.G., Torres N., Melo M.T.V. 1964. Geologia das quadriculas Barra do Cuité e Conselheiro Pena, MG. Rio de Janeiro, DNPM, Relatório do Arquivo Técnico do DGM, 64, 285p.

Berdiel M.T. 1995. Mécanismes d'intrusion des granites supracrustaux: modèles analogiques et exemples naturels.
Thèse, Mémoire 62, Université de Rennes, 258p.

Bilal E., Nalini Jr. H.A., Horn H., Correia Neves J.M., Giret A., Fuzikawa K., Fernandes M.L., Mello F.M., Moutte J. 1998. Granitóides neoproterozóicos da região do Rio doce, Minas Gerais, Brasil. In: Congresso Brasileiro de Geologia, 40, Belo Horizonte, Anais, p. 512-512.

Blumenfeld P. 1983. Lê 'tuilage' dês megacristaux', um critère d'écoulement rotacionnel pour lê fluidalités dês roches magmatique. Application au granite de Barbey-Sérou (Vosges, France). Bull. Soc. Geol. Fr., 25:309-318. 
Blumenfeld P. \& Bouchez J.L. 1988. Shear criteria in granite and migmatite deformated in the magmatic and solid states. J. Struct. Geol., 10:361-372.

Brun J.P. 1981. Instabilités gravitaires et deformation de la crô̂te continentale. Aplication au dévelloppement des domes et plutons. Université de Rennes I.

Brun J.P. \& Pons J. 1981. Strain pattern of pluton emplacement in a crust undergoing non-coaxial deformation. J.Sructur. Geol., 3:219-229.

Castro A. 1987. On granitoid emplacement and relacted structures. A review. Geologische Rundschau, 76(1):101124.

Cerny P. 1990. Distribution, affiliation and derivation of rareelement granitic pegmatites in Canadian Shield. Geologische Rundschau, 79:183-226.

Clemens J.D. \& Mawer C.K. 1992. Granitic magma transport by frature propagation. Tectonophysics, 204:339-360.

Davies F.B. 1982. Pan-African granite intrusion in response to tectonic volume changes in ductile shear zone from Northern Saudi Arabia. J. Geol., 90:467-483.

Den-Tex E. 1966. Aperçu pétrologique et structural de la Galice crystalline. Leidse Geol.Mededelingen, 36:211-222.

D'lemos R.S.D., Brown M., Strachan R.A. 1992. Granite magma generation, ascent and emplacement within a transpressional orogen. J. Geol. Soc. London, 149:487490.

England R.W. 1990. The identification of granitic diapers. $J$. Geol. Soc. London, 147:931-933.

Etheridge M.A., Wall V.J., Vernon R.H. 1983. The role of the fluid phase during regional metamorphism and deformation. J. Metamor. Geol., 1:205-226.

Fanton J.J., Arioli E.A., Moura O.J.M. 1978. Pegmatitos da região de Galiléia-Mendes Pimentel, MG. In: SBG, Cong. Bras. Geol., 30, Anais, p.1770-1781.

Figueiredo M.C.H. \& Campos Neto M.C. 1993. Geochemistry of the Rio Doce magmatic arc, Southeastern Brazil. Anais da Academia Bras. de Ciências, 65:63-81.

Fontes C.Q., Netto C., Costa M.R.A., Baltazar O.F., Silva S.L., Vieira V.S. 1978. Projeto Jequetinhonha. Belo Horizonte, DGM, DNPM/CPRM, Relatório Final. No 2787, Vol. 1.

Guineberteau B., Bouchez J.L and Vigneresse J.L. 1987. Mortagne Granite Pluton (France) emplaced by pullapart along a shear zone: structural and gravimetric arguments and regional implication. Bull. Geol. Soc. Amer., 99:763-770.

Guillet P., Bouchez J.L, Vigneresse J.L. 1985. Le complexe granitique de Plouaret. Mise en evidence struturale et gravimétrique de diapers emboité. Bull. Soc. Géol. Fr., 8:503-513.

Hanmer S. \& Vigneresse J.L. 1980. Mise en place de diapers syntectonique dnas la chaîne hercynienne: exemple des massifs leucogranitiques de Locronan e $\mathrm{t}$ de Pontivy (Bretagne Central). Bull. Soc. Géol. France (7), t. XXII(2):193-202.

Hasui Y., Carneiro C.D.R., Coimbra A.M. 1975. The Ribeira folded belt. Rev. Bras. Geoc., 5:257-266.

Hutton D.H.W. 1982. A tectonic model for the emplacement of the Main Donegal granite, NW Ireland. J. Geol. Soc. London, 139:61-631.
Hutton D.H.W., Dempster T.J., Brown P.E., Decker S.D. 1990. A new mechanism of granite emplacement: intrusion in active extensional zone. Nature, 343:452-455.

Hutton D.H.W. 1988. Granite emplacement mechanism and tectonic controls: Inferences from deformation studies. Royal Soc Ed Trans, 79:245-255.

Hutton D.H.W. \& McErlean M. 1991. Silurian and Early Devonian sinistral deformation of the Ratagain granite, Scotland: constraints on the age of Caledonian movements on the Great Glen fault system. J. Geol. Soc. London, 148:1-4.

Issa Filho A., Moura O. J. M., Fanton J.J. 1980. Reconhecimento de pegmatitos da província oriental brasileira entre Aimorés e Itambacuri, MG. In: Congresso Brasileiro de Geologia, 31, Balneário de Camboriú-SC, Anais, v. 3:1552-1563.

Kesler D.M. 1976. Occurrences, devellopment, and longrange outlook of lithium-pegmatite ore in the Carolinas. United States Geological Survey, Professional Paper 1005 , p. 55-65.

Lagard J.L., Omar S.A., Roddaz B. 1990. Structural characteristics of granitic plutons emplaced during weak regional deformation: example from late Carboniferous plutons, Morocco. J.Structural Geology, 12(7):805-821.

Lagarde J.L., Capdevila R., Fourcade S. 1992. Granites et collision continentale: l'exemple des granitoïdes carbonifères dans la chaîne hercynienne ouest-européenne. Bull.Soc.géol.France, 163(5):597-610.

Mello F.M. 2000. Litogeoquímica e química mineral do Maciço charnoquítico Aimorés/MG. Tese de Doutoramento. Instituto de Geociências da USP, 217p.

Machado R. \& Endo I. 1993. O Cinturão de Cisalhamento Atlântico: um exemplo de tectônica transpressional neoproterozóica. In: Simp. Nac. Est. Tect. Boletim, 4, Belo Horizonte, Atas, p. 188-191.

Marsh B.D. 1982. On the mechanics of igneous diapirism, stoping and zone melting. Am. J. Sci., 282:808-855.

Martins V.T. 2000. Geologia isotópica do plutonismo Neoproterozóico da Faixa Araçuaí, região nordeste de Minas Gerais. Dissertação de Mestrado. Instituto de Geociências, Universidade de São Paulo, 187p.

Martins V.T., Teixeira W., Noce C.M., Pedrosa-Soares A.C. 2004. Sr and Nd characteristics of Brasiliano/Pan-African granitoid plutons of the Araçuaí Orogen, Southeastern Brazil :tectonic implications. Gondwana Research, 7(1):75-89.

McCaffrey K.J.W. 1992. Igneous emplacement in a transpressive shear zones: Ox Montains igneous complex. $J$. Geol. Soc. London, 149:221-235.

Moura O.J.M., Fanton J.J..Arioli E.A. 1978a. Pesquisa de pegmatitos na Serra do Urucum, Médio Rio Doce, MG. In: Congresso Brasileiro de Geologia, 30, Recife, Anais, 4:1836-1850.

Moura, O.J.M., Fanton J.J., Arioli E.A. 1978b. Geologia da região de Galiléia - Mendes Pimentel, Minas Gerais. Congresso Brasileiro de Geologia, 30, Recife, Anais, 1:26-37.

Nalini Jr. H.A. 1997. Caractérisation des suites magmatiques néoprotérozö̈ques de la region de Conselheiro Pena et Galiléia (Minas Gerais, Brésil). Etude géochi- 
mique et structurale des suites Galiléia et Urucum et relations avec les pegmatites à éléments rares associées. Tese de Doutoramento, Saint Etienne, Ecole des Mines de Saint Etienne et Ecole des Mines de Paris.

Nalini Jr. H.A., Bilal E., Paquette J.L., Pin C., Machado R. 2000a. Geochronologie $\mathrm{U}-\mathrm{Pb}$ et géochimie isotopique Sr-Nd des granitoides neoproterozoiques des suites Galileia et Urucum, vallée du Rio Doce, Sud-Est du Brésil. Compte Rendu Acad. Sci. Paris, 331:459-466.

Nalini Jr. H.A., Bilal E., Correia Neves J.M. 2000b. Syn-collisional peraluminous magmatism in the Rio Doce region: mineralogy, geochemistry and isotopic data of the Urucum suite (eastern Minas Gerais state, Brazil). Rev. Bras. Geoc., 30(1):120-125.

Nalini Jr. H.A., Bilal E., Machado R. 2005. Geoquímica e petrogênese da suíte Galiléia : um exemplo de magmatismo tipo-I metaluminoso pré-colisional Neoproterozóico da região do médio Vale do Rio Doce. Revista Brasileira de Geociências, 35(4- suplemento):23-34.

Noce C.M., Macambira M.J.B., Pedrosa-Soares, A.C., Martins, V.T.S., Ferreira, D.C. 1999. Chronology of late proterozoic-cambrian granitic magmatism in the Araçuaí belts, eastern Brazil, based on dating by single zircon evaporation. In: South Americam Symposium on Isotope Geology, 2, Córdoba, Argentina, Atas, p. 86-89.

Noce C.M. \& Macambira M.J.B. 2000. Chronology of late proterozoic-cambrian granitic magmatism in the Araçuaí belts, eastern Brazil, based on dating by single zircon evaporation. Rev. Bras. Geoc., 30(1):25-29.

Paterson S.R., Vernon R.H., Tobisch O.T. 1989. A review of criteria for the identification of magmatic and tectonic foliations in granitoids. J. Structural Geology, 1(3):349363.

Paterson S.R. \& Fowler T.K. 1993. Re-examining pluton emplacement processes. Jour. Struct. Geol., 15:191-206.

Petford N., Lister J.R., Kerr R.C. 1994. The ascent of felsic magmas in dykes. Lithos, 32:161-168.

Pedrosa-Soares A.C., Wiedemann C.M., Fernandes M.L.S., Faria L.F., Ferreira J.C.H. 1999. Geotectonic significance of the Neoproterozoic granitic magmatism in the Araçuaí belt, Eastern Brazil: a model and pertinent questions. Rev. Bras. Geoc., 29:57-64.

Pedrosa-Soares A.C. \& Wiedemann-Leonardos C.M. 2000. Evolution of the Araçuaí Belt and its conection to the Ribeira Belt, eastern Brazil. In: Cordani U.G., Milani E.J., Thomaz Filho A., Campos D.A. (eds.) Tectonic Evolution of South America. Rio de Janeiro, p. 265-286.

Pedrosa-Soares A.C., Noce, C.M., Wiedemann C.M. Pinto C.P. 2001. The Araçuaí-West-Congo Orogen in Brazil: an overview of a confined orogen formed during Gondwanaland assembly. Precambrian Research, 110:307323.

Pitcher W.S. 1979. The nature, ascent and emplacement of granitic magmas. J. Geol. Soc. London, 136:627-662.

Pitcher W.S. \& Berger 1972. The geology of Donegal: study of granite emplacement unroofing. London,John Wiley.

Pons J. 1982. Un modele d'évolution de complexes plutoniques: gabbros et granitóides de la Sierra Morena Occidentale (Espagne). Thèse de doctorat, Toulouse, France, $451 \mathrm{p}$.
Ramberg H. 1970. Model studies in relation to intrusion of plutonic bodies. In: Newall G. \& Rast N. (eds.) Mechanism of igneous intrusion. Gallery Press, Leverpool, 261-286.

Rossovskyi L.N. \& Chmyrev V.M. 1977. Disribution patterns of rare-metal pegmatites in the Hindu Kush (Afghanistan). International Geology Review, 19:511-520.

Sanderson D.J. \& Marchini W.R.D. 1984. Transpression. J. Structural Geol. 6(5):449-458.

Siga Jr. O. 1986. A evolução geotectônica da porção nordeste de Minas Gerais, com base em interpretações geocronológicas. Dissertação de Mestrado. Instituto de Geociências, Universidade de São Paulo, 140p.

Shaw H.R. 1980. Fractures mechanisms of magma transport from the mantle to the surface, In: Hargraves R.B.(ed.) Physics of Magmatic Processes. New York, Princeton University Press, p. 201-264.

Silva J.M.R., Lima M.I.C., Veronese V.F., Ribeiro Jr., R.N., Rocha R.M., Siga Jr. O. 1987. Geologia da Folha SE.24Rio Doce. R. de Janeiro, Projeto Radambrasil, 34, 544p.

Silva L.C., Armstrong R., Noce C.M., Carneiro M., Pimentel M., Pedrosa-Soares A.C., Leite C. A., Vieira V.S., Silva M.A., Paes V.J.C., Cardoso-Filho J.M. 2002. Reavaliação U-Pb SHRIMP em terrenos pré-cambrianos brasileiros : Parte II : Orógeno Araçuaí, Cinturão Mineiro e Cráton São Francisco Meridional. Rev. Bras. Geoc., 32(4):513-528.

Tuller M.P. 1993. Colatina. Folha SF.24-Y-C-VI. Estado do Espírito Santo. Escala 1: 100.000. Programa Levantamentos Geológicos Básicos do Brasil. Org. por Manoel Pedro Tuller, Brasília, DNPM-CPRM, 163p.

Tullis J.A. 1983. Deformation of feldspars. In: Ribbe P.H. (ed.) Feldspar Mineralogy. $2^{\text {nd }}$ ed., Mineralogical Society of America Short Couses Notes, 2, p.297-323.

Turner F.J. \& Weiss L.E. 1963. Structural Analysis of Metamorphic Tectonites. New York, McGraw Hill, 545 p.

Van der Molen I. \& Paterson M. S. 1979. Experimental deformation of partially melted granite. Contr. Mineral. Petrol., 70:299-318.

Vauchez A. 1980. Ribbon texture and deformation mechanisms in quartzin a mylonitized granite of Great Kabylia (Algeria). Tectonophysics, 67:1-2.

Vernon R.H. 1986. K-feldspath megacrysts in granites - phenoxrysts, not porphyroblasts. Earth Sci. Rev., 23:1-63.

Vieira V.S. 1993. Colatina. Folha SF.24-Y-C-VI. Estado do Espírito Santo. Escala 1: 100.000. Programa Levantamentos Geológicos Básicos do Brasil. Org. por Valter Salino Vieira, Brasília, DNPM-CPRM, $175 p$.

Vigneresse J.L \& Brun J.P. 1983. Les leucogranites armoricains marqueurs de la déformation régionale: apport de la gravimétrie. Bull. Soc. Géol. Fr., 25:357-366.

Wiedemann C.M. 1993. The evolution of the Early Paleozoic, Late- to Post-Collisional Magmatic Arc of the Coastal Mobile Belt in the State of Espírito Santo, eastern Brazil. An. Acad. Bras. Ciênc., 65:163-181.

Manuscrito ID 11732 Submetido em 09 de julho de 2008 Aceito em 17 de dezembro de 2008 Sistema eletrônico de submissão 